\title{
Media Exposure and Reproductive Health Behaviour Among Young Females in Ghana
}

By

Stephen O. Kwankye and Eric Augustt, Regional Institute for Population Studies (RIPS), University of Ghana, Legon, Accra, Ghana

\begin{abstract}
The study is premised on the hypothesis that a young woman's exposure to the media increases her knowledge about sexual and reproductive health risks, which in turn, influences her to adopt positive sexual and reproductive behaviour. Using the 2003 Ghana Demographic and Health Survey dataset on women 15-24 years, the study finds that although a young woman's exposure to the newspapers positively affects her sexual and reproductive behaviour, overall no consistent and statistically significant results were produced particularly with reference to the electronic media (radio and television). The conclusion is that mere exposure to the media may not be enough to change one's sexual and reproductive behaviour if the contents of the particular media source do not positively address sexual and reproductive health issues, a subject which the study calls for further research.
\end{abstract}

Key Words: Media exposure, reproductive health behaviour, young females, family planning, Ghana. 


\section{Introduction}

Young persons of 15-24 years constitute a sizeable proportion of the population in most countries of sub-Saharan Africa. In Ghana, young females $15-24$ years make up $18.4 \%$ of the total population of women, but more than one-third (39\%) of women in the reproductive ages 15-49 years (Ghana Statistical Service, 2002). With a built-in population momentum, i.e., with $40 \%$ of the population less than 15 years (Population Reference Bureau, 2005), the 15-24-year-old population would continue to be relevant with respect to reproductive health issues in the country.

Information, education and communication are increasingly becoming important components of the technological and behavioural transformation of the human population. The world is fast becoming a global village. Thus, the traditional mechanism of grandmothers playing effective roles in educating young females about their sexuality and childbearing in most of Africa is steadily being overtaken by the information and communication technology. Yet, as these generational linkages are fast being eroded, no formal sexeducation, especially on family planning, has risen to fill the void (Centre on Population Options, 1992).

In Ghana, population and family life education has been recommended and adopted as part of the Social Studies Curriculum of basic school education in the country. While this is a welcome development, it is a fact that such a programme would reach only young persons who are in school and exclude a considerable proportion of their colleagues especially the females who may be out of school due often to having dropped out of school for various sociocultural and economic reasons.

In a study focused on how school children learn about sex and love in Akropong, Essah (2006) describes the inadequacy of the educational system in offering sex education to school pupils at early ages. From Essah's study, it was revealed that sex education is not much institutionalised at the Junior Secondary School level considering that the "Life Skills" course in which sex education was integrated had been discontinued, with many schools not making any time for it on their teaching time tables. Even where sex education is taught, it comes up too late, towards the end of Form Three (Essah, 
Stephen O. Kwankye and Eric Augustt: Media Exposure and Reproductive Health Behaviour Among Young Females in Ghana

2006), perhaps at a time when some of the young pupils might have been involved in behaviours that impact negatively on their reproductive health. Consequently, the school as a good source of sexual and reproductive health information and education is limited.

Ghana is currently experiencing fertility transition, with total fertility rate dropping from 6.4 in 1988 to 5.5 in 1993 and to an average of 4.4 in 1998 and 2003 (Ghana Statistical Service and Macro International Inc., 1989, 1994, 1999 and 2004). This shows some persistent and seemingly dramatic fall in fertility since 1988 (Nyarko, 2005). The contribution of adolescents 15-19 years to fertility in Ghana has averaged 10\% (see 1989, 1994, 1999 and 2004 GDHS reports). Though not a big contribution, reproduction among females of such young ages carries with it a number of possible outcomes. The impact of these on the development of the women could be negative namely, an unplanned/unwanted pregnancy, sexually transmitted infections (STIs) or HIV/AIDS infection and, dropping out of school. In addition, a consideration of an abortion and its associated complications could lead to death or life-long impairment to the reproductive system of the woman. For example, some pregnant girls have been reported to use all kinds of strange methods to get rid of an unwanted pregnancy including grounded bottles mixed with water or beer which they drink (Essah, 2006). Apart from the risks young women may be exposed to, early sexuality and/or childbearing could foreclose their socio-economic progression in life.

From a report on the assessment of sexual and reproductive health needs in Ghana (Nabila et. al., 1996), 16\% of teenage girls could correctly identify when, during a woman's menstrual cycle, she was most likely to become pregnant. Inadequate knowledge about reproductive health, therefore, could contribute to high risks of unplanned pregnancies, sexually transmitted infections (STIs) and HIV/AIDS, etc., among young women in Ghana. One mechanism for information provision is the media, made up of print (newspapers and magazines) and electronic (radio and television). In Ghana, following the liberalisation of the airwaves since the year 2000, a number of radio and television stations have emerged on the media landscape. There are also several private newspapers currently on the newsstands in the country. These media channels provide information in addition to offering convenient platforms for discussions on all 
issues relating to the political, socio-cultural and economic spheres of life.

This paper attempts to examine the extent, to which these media channels, i.e., radio, television and newspapers, impact on the knowledge and behaviour of young women in Ghana with respect to their sexuality and reproductive health. It examines the possible impact of the media on sex initiation and the timing of marriage, knowledge of the ovulatory cycle, contraceptive knowledge and use, childbearing and pregnancy termination among young females 15-24 years in Ghana.

\section{Theoretical Framework}

The theoretical basis of this study hinges on the fact that there is no clear-cut relationship between access to the mass media and reproductive health behaviour or practices. According to Ling (1990), "it is almost an article of faith among development communication practitioners that well-designed public programmes that combine media communication with community education will contribute to the adoption of positive public health practices. What has not yet been realised by many health professionals and the public is that the same modern communications technology, via the mass media, is now a factor in the increasing incidence of diseases that are related to lifestyles". This is an indication that while the mass media seeks to inform and change behaviour, it could at the same time be counterproductive.

All over the world, changing behaviour could be difficult. Often laws that threaten severe sanctions or penalties fail to change people's behaviour. Behaviour change, however, often is a gradual step-by-step process dependent on a person's experiences and his/her perception of the personal importance of the change (McCuire, 1981). Studies that have attempted to examine the impact of access to the mass media on behaviour change have so far produced little or no effects or have simply led to conflicting results (McCurie, 1986). Reasons cited for lack of impact include poor quality media programmes or low coverage. On the other hand, its impact could be obscured by other influences the target population may be exposed to. 
Stephen O. Kwankye and Eric Augustt: Media Exposure and Reproductive Health Behaviour Among Young Females in Ghana

It must be noted that notwithstanding the inconsistent observed impact of the media on behaviour changes, one thing that is clear is that the media informs as well as educates and if the right information is provided, it is likely that persons who have access to a particular type of media would have a faster change in behaviour.

Theoretically, it is assumed that persons who are regularly exposed to the media are more likely than their counterparts with little or no exposure to have higher knowledge about reproductive health matters and consequently, their behaviour would be less prone to risks. This is premised on the conception that the media provides the right information, which could affect the behaviour change process. It is also to be noted that one's access to the media is also linked to his/her education and place of residence.

The proliferation of media houses and facilities is also linked to the modernisation and globalisation process of development. Consequently, premised on the assumption that the media's main role is to provide accurate information and educate the general population, it is hypothesised that young women with higher access to the media sources would have a higher knowledge of reproductive health issues and as such have relatively less risky sexual behaviours or practices. The analysis also presents the unique opportunity to assess the notion that is often put across especially within traditional society that modernisation and access to the media among persons at young ages could result in sexual promiscuity.

\section{Data and Methodology}

The paper uses the 2003 Ghana Demographic and Health Survey (GDHS) data collected from a nationally representative survey of 5,691 women aged 15-49 years and 5,015 men aged 15-59 years. For the purpose of this paper, however, only data covering young females of 15-24 years are used for the analysis. The paper is, therefore, based on a total sample of 2,160 females, made up of 1,148 of age 15-19 years and 1,012 of 20-24 years. Basically, the analysis seeks to make comparisons between the 15-19 and 20-24 age groups. The analysis employs simple cross tabulations as well as multiple and logistic regression analyses to present the results. Both statistical techniques 
enable us estimate the degree of variation in the dependent variables that are contributed to by each independent variable.

The statistical analysis uses the following variables namely, age at first sex, number of children ever born, knowledge of the ovulatory cycle, ever use and current use of any method of family planning as the dependent variables. The independent variables however, include the current age, educational level, place of residence (rural or urban) and the frequency with which the young woman listens to the radio, reads newspapers or watches television.

\section{Results}

\section{Background Characteristics}

Analysis of the data indicates that overall, the majority of the young females had attained secondary level of education $(60 \%)$ but one out of six of them has had no formal education. Comparing the two age groups, however, shows that a relatively higher proportion of the older females (20-24) have no education than their counterparts of $15-19$ years, i.e., $20 \%$ compared with $12 \%$. At the same time, a higher proportion of females of 15-19 years have had secondary level of education relative to those aged 20-24 years. This suggests some improvements in the education of girls in Ghana during the past five years with respect to secondary level of education. However, a higher proportion of females aged 20-24 years (5.1\%) have attained higher education compared with less than one percent among females aged 15-19 years. This is perhaps due to the fact that by virtue of their young ages, not many of the 15-19-year-olds could practically be at higher levels of education.

In terms of rural and urban place of residence, the total sample has a higher proportion from urban (54\%) compared with the rural $(46 \%)$ areas. This compares with the GDHS report of $48.4 \%$ urban and $51.6 \%$ rural for the entire sample of women 15-49 years (Ghana Statistical Service et al., 2004). This suggests that a higher proportion of the young females (15-24 years) live in urban places compared with the older women who were more than 24 years. 
Stephen O. Kwankye and Eric Augustt: Media Exposure and Reproductive Health Behaviour Among Young Females in Ghana

\section{Frequency of Exposure to the Media}

Analysis of the data with respect to access to newspapers, radio and television (Table 1) shows that two in three young females in Ghana do not read any newspaper or magazine at all, and only 3\% of them read it almost everyday. The situation is, however, quite different for radio and television, which have $13 \%$ and $30 \%$ respectively not listening to or watching it at all. It, therefore, would appear that information dissemination targeting the female youth would be more appropriate using the radio or television than through the newspapers or magazines.

There are, however, variations in each case pertaining to age, education and place of residence. In terms of the newspaper, a relatively smaller proportion of the females of age 15-19 years do not read any newspaper at all in comparison with those of 20-24 years. This notwithstanding, a slightly higher proportion of the 20-24 age group read a newspaper almost everyday relative to the 15-19 year group. There is also some direct relationship between education and reading of newspapers among the young females. It is, however, noted that only one in four of the females read a newspaper almost everyday. It is again to be expected that more urban dwellers would read newspapers than persons resident in rural areas. This is because apart from the fact that newspapers may not be available in many rural areas in Ghana, most of the rural dwellers may not be able to buy the newspapers let alone read them.

Table 1 also shows that for both radio and television, media access increases with higher education. As expected, urban dwellers have a higher degree of access to both radio and television. There is, however, not much variation among the women of 15-19 years and their counterparts of 20-24 years comparing access to the radio and television. 
Table 1: Percent distribution of young females’ (15-24 years) frequency of exposure to the media by age group, educational level and place of residence

\begin{tabular}{|c|c|c|c|c|c|c|}
\hline Background & & Less than & At least Almost & & tal & \\
\hline Characteristics & Not at all & once a week & once a week & everyday & $\%$ & Number \\
\hline Newspaper & & & & & & \\
\hline Age & & & & & & \\
\hline $15-19$ & 69.2 & 11.1 & 16.7 & 3.0 & 100.0 & 1,147 \\
\hline $20-24$ & 74.5 & 11.2 & 10.9 & 3.4 & 100.0 & 1,010 \\
\hline Level of educa & & & & & & \\
\hline No education & 100.0 & 0.0 & 0.0 & 0.0 & 100.0 & 339 \\
\hline Primary & 93.9 & 4.2 & 1.7 & 0.2 & 100.0 & 472 \\
\hline Secondary & 58.9 & 16.5 & 20.4 & 4.2 & 100.0 & 1,292 \\
\hline Higher & 9.5 & 11.3 & 54.7 & 24.5 & 100.0 & 53 \\
\hline Place of reside & & & & & & \\
\hline Urban & 59.0 & 14.7 & 21.1 & 5.2 & 100.0 & 998 \\
\hline Rural & 86.6 & 6.9 & 5.7 & 0.8 & 100.0 & 1,159 \\
\hline Total $\quad \%$ & 71.8 & 11.1 & 14.0 & 3.2 & 100.0 & - \\
\hline Number & 1,548 & 239 & 301 & 69 & - & 2,157 \\
\hline Radio & & & & & & \\
\hline Age & & & & & & \\
\hline $15-19$ & 13.8 & 13.2 & 30.5 & 42.5 & 100.0 & 1,148 \\
\hline $20-24$ & 11.0 & 11.0 & 29.3 & 48.7 & 100.0 & 1,012 \\
\hline Level of educa & & & & & & \\
\hline No education & 28.4 & 21.6 & 25.4 & 24.6 & 100.0 & 338 \\
\hline Primary & 16.7 & 13.2 & 30.7 & 39.4 & 100.0 & 473 \\
\hline Secondary & 7.3 & 9.5 & 31.7 & 51.5 & 100.0 & 1,294 \\
\hline Higher & 0.0 & 6.8 & 9.7 & 83.5 & 100.0 & 53 \\
\hline Place of reside & & & & & & \\
\hline Urban & 8.6 & 11.6 & 29.9 & 49.9 & 100.0 & 1,160 \\
\hline
\end{tabular}

86 


\begin{tabular}{|c|c|c|c|c|c|c|}
\hline Rural & 16.9 & 12.9 & 30.0 & 40.2 & 100.0 & 1,000 \\
\hline Total & 12.5 & 12.2 & 29.9 & 45.4 & 100.0 & - \\
\hline Number & 269 & 263 & 647 & 981 & - & 2,160 \\
\hline \multicolumn{7}{|l|}{ Television } \\
\hline $15-19$ & 30.3 & 15.2 & 24.9 & 29.6 & 100.0 & 1,146 \\
\hline $20-24$ & 29.7 & 18.3 & 23.7 & 28.3 & 100.0 & 1,012 \\
\hline \multicolumn{7}{|l|}{ Education Level } \\
\hline No education & 61.9 & 12.7 & 13.5 & 11.9 & 100.0 & 339 \\
\hline Primary & 40.6 & 19.2 & 23.0 & 17.2 & 100.0 & 470 \\
\hline Secondary & 19.0 & 17.1 & 28.0 & 35.9 & 100.0 & 1,294 \\
\hline Higher & 1.9 & 7.7 & 15.4 & 75.0 & 100.0 & 52 \\
\hline \multicolumn{7}{|c|}{ Place of Residence } \\
\hline Urban & 14.4 & 19.8 & 28.2 & 43.5 & 100.0 & 999 \\
\hline Rural & 48.3 & 13.9 & 19.8 & 12.1 & 100.0 & 1,160 \\
\hline Total $\quad \%$ & 30.0 & 16.6 & 24.4 & 29.0 & 100.0 & - \\
\hline Number & 648 & 359 & 525 & 626 & - & 2,158 \\
\hline
\end{tabular}

Source: Computed from 2003 GDHS data. 


\section{Age at First Sexual Activity}

The investigation into the variation (of the respondents) in age at first sexual activity does not show consistent results. For example, with respect to reading of newspapers, the highest mean age at first sex is recorded among females who read it at least once a week (20.1 years) but for television, the highest mean age at first sex is among those who watch it less than once a week (17.4 years) and the lowest among those who never watch television at all (presumably, these are the rural dwellers). On the other hand, analysis of radio's possible impact on initiation of first sex, depicts females who listen to the radio less than once a week to have the lowest mean age at first sex, while the highest mean age at first sex is recorded among their counterparts who listen to the radio almost everyday.

It is important to note that in all three types of media, a higher proportion of females initiate sex within ages 15-19 years irrespective of frequency of media exposure. Within ages 20-24 years, however, the proportion of females who initiate sex within ages 20-24 years is highest among those who are almost everyday exposed to one of the three types of media compared with their counterparts with lesser or no media exposure. This plausibly suggests some positive impact of the media on the initiation of first sex among the females; that is regular access to newspapers, radio and television could result in the postponement of first sex among the females, a development, which is quite positive.

The relationship between one's media exposure and initiation of sex is, however, influenced by a number of factors. These include the young person's level of education, place of residence (whether rural or urban), the household environment (including household assets and encouragement or otherwise from parents or siblings) towards the use of the media as sources of information and education on sexuality and reproductive health.

\section{Age at First Marriage}

Assessing the impact of the media on age at first marriage among the young females suggests the likelihood of persons who have regular access to all three types of media marrying late compared with their counterparts who never have access to any of the 
Stephen O. Kwankye and Eric Augustt: Media Exposure and Reproductive Health Behaviour Among Young Females in Ghana

media channels. The analysis also shows that for access to newspapers, mean age at first marriage is 17.1 years among females who never read any newspaper at all and 19.5 years among those who read it almost everyday. It is also to be noted that for radio, the corresponding mean ages at first marriage are 16.8 years and 17.4 years while for television, the means are 16.9 years and 17.7 years. The analysis seems to suggest that when women are exposed to reading newspapers, listening to the radio or watching television regularly, they are likely to postpone their marriage and thereby, concentrate on their education.

The above findings have implications for rural and urban places of residence. In Table 1, we find that almost half of the respondents from the rural areas do not watch television and more than $80 \%$ do not read newspapers compared with less than $15 \%$ in either case in the urban area. This shows why lower median age at first marriage has been found among rural respondents in Ghana compared with urban dwellers (see Ghana Demographic and Health Survey, 1988, 1993, 1998 and 2003).

\section{Knowledge and Use of Contraceptives}

Information on family planning methods and usage is usually disseminated through newspaper, radio and television outlets throughout the country. From the analysis, it is observed that knowledge of any method of contraception is quite high $(95.4 \%$ among females $15-19$ years and $98.5 \%$ for the 20-24 year age group figures not shown). This compares with $97.7 \%$ for all women 15-49 years in Ghana (Ghana Statistical Service and Macro International Inc., 2004). With reference to the frequency of exposure to the media types, the analysis further shows that on the whole, knowledge of contraception is relatively higher among young females who regularly (almost everyday) read newspapers, listen to the radio or watch television. For example, while knowledge among women who do not listen to the radio at all is $88.5 \%$, their counterparts who regularly listen to it record $98.7 \%$ knowledge of contraception, representing a difference of $10 \%$ between the two groups.

The study further examined the young females who have ever had sex based on whether or not they have ever used any 
contraceptive methods in the past and their variation with respect to their access to the three media types. The analysis further shows that overall the proportion of young females who have never used any method of family planning is $43 \%$ with $10 \%$ and $47 \%$ ever using traditional and modern methods respectively. Here, it is noted that the proportion never using any family planning method is lower for all young females with some exposure to the three media types than the average for all the young females (i.e., $43 \%$ ) except young females who are exposed to the radio less than once a week among whom 52\% have never used any family planning method (Table 2).

Table 2 also shows that the proportion ever using a modern method of family planning increases with higher frequency of reading newspapers, listening to the radio and watching television. Specifically, we note that $43.8 \%$ of the young females who have ever used any method of family planning have used condoms, $21.1 \%$ have used periodic abstinence, $14 \%$ have used the pill and about $10 \%$ have adopted injections (figure not shown in the table). 
Table 2: Percent distribution of sexually active young females by use of birth control methods by frequency of exposure to different media

\begin{tabular}{|c|c|c|c|c|c|}
\hline \multirow[b]{2}{*}{ Contraceptive use } & \multicolumn{4}{|c|}{ Frequency of media exposure } & \multirow[b]{2}{*}{ Total } \\
\hline & Not at all & $\begin{array}{l}\text { Less than } \\
\text { once a week }\end{array}$ & $\begin{array}{l}\text { At least } \\
\text { once a week }\end{array}$ & $\begin{array}{l}\text { Almost } \\
\text { everyday }\end{array}$ & \\
\hline \multicolumn{6}{|l|}{ Ever use } \\
\hline \multicolumn{6}{|l|}{ Newspaper } \\
\hline Never used & 48.1 & 25.4 & 22.1 & 25.0 & 43.2 \\
\hline Used traditional methods & 9.5 & 15.6 & 8.9 & 5.0 & 9.9 \\
\hline Used modern methods & 42.4 & 59.0 & 69.0 & 70.0 & 46.9 \\
\hline Total number & 1,043 & 122 & 113 & 20 & 1,300 \\
\hline \multicolumn{6}{|l|}{ Radio } \\
\hline Never used & 66.5 & 51.9 & 40.4 & 36.3 & 43.2 \\
\hline Used traditional methods & 7.9 & 8.7 & 9.0 & 11.4 & 9.9 \\
\hline Used modern methods & 25.6 & 39.4 & 50.6 & 52.3 & 46.9 \\
\hline Total number & 164 & 160 & 391 & 587 & 1,300 \\
\hline \multicolumn{6}{|l|}{ Television } \\
\hline Never used & 62.5 & 39.0 & 32.0 & 30.9 & 43.2 \\
\hline Used traditional methods & 5.7 & 13.6 & 12.8 & 9.8 & 9.9 \\
\hline Used modern methods & 31.8 & 47.4 & 55.2 & 59.3 & 46.9 \\
\hline Total number & 437 & 236 & 319 & 307 & 1,300 \\
\hline \multicolumn{6}{|l|}{ Current use } \\
\hline \multicolumn{6}{|l|}{ Newspaper } \\
\hline Never used & 80.3 & 63.9 & 52.2 & 50.0 & 75.8 \\
\hline Used traditional methods & 5.8 & 9.0 & 9.7 & 10.0 & 6.3 \\
\hline Used modern methods & 13.9 & 27.1 & 38.1 & 40.0 & 17.9 \\
\hline
\end{tabular}




\begin{tabular}{|c|c|c|c|c|c|}
\hline Total number & 1,043 & 122 & 113 & 20 & 1,300 \\
\hline \multicolumn{6}{|l|}{ Radio } \\
\hline Never used & 89.6 & 83.8 & 75.2 & 69.8 & 75.8 \\
\hline Used traditional methods & 3.0 & 3.8 & 8.4 & 7.2 & 6.3 \\
\hline Used modern methods & 7.4 & 12.4 & 16.4 & 23.0 & 17.9 \\
\hline Total number & 164 & 160 & 391 & 587 & 1,300 \\
\hline \multicolumn{6}{|l|}{ Television } \\
\hline Never used & 85.4 & 73.3 & 69.9 & 70.0 & 75.8 \\
\hline Used traditional methods & 3.2 & 9.7 & 10.3 & 4.9 & 6.3 \\
\hline Used modern methods & 11.4 & 17.0 & 19.8 & 25.1 & 17.9 \\
\hline Total number & 437 & 236 & 319 & 307 & 1,300 \\
\hline
\end{tabular}

Source: Computed from 2003 GDHS data. 
Stephen O. Kwankye and Eric Augustt: Media Exposure and Reproductive Health Behaviour Among Young Females in Ghana

The results for current use of birth control methods are similar to those presented for ever use. Current use of modern methods generally increases with higher frequency of access to newspapers, radio or television. The suggestion is that as young females regularly read newspapers, listen to radio or watch television, the likelihood is there for them to use contraceptives whenever they choose to have sex. It must be pointed out, however, that ever use of contraception is higher than current use, a situation, which suggests irregular contraceptive usage among sexually active young females in the country.

\section{Knowledge of Ovulatory Cycle}

Knowledge of when, in the ovulatory cycle, a woman is likely to be pregnant could serve as useful information to assist the woman to prevent or avoid a pregnancy by either using a contraceptive or abstaining from sex completely during the period of ovulation. More specifically, basic knowledge of reproductive physiology is considered useful for the successful practice of coitus related methods of pregnancy prevention particularly with respect to the rhythm method (Central Statistical Office et al, 1997). From Table 3, overall, the results indicate that about one in four of the young females correctly stated the occurrence of ovulation within the middle of the menstrual cycle. This is lower than the results from the 2003 GDHS for all women, which is $29.4 \%$ (Ghana Statistical Service et al, 2004). Similar low knowledge of the ovulatory cycle has been found by Essah (2006) where one in 10 of the pupils she studied in Akropong knew of the time during the menstrual cycle that a female is most likely to become pregnant. This suggests a generally poor knowledge regarding the period of ovulation among young women in Ghana, a situation that could predispose some of them to obviously avoidable pregnancies.

Relating knowledge of ovulatory cycle to media exposure, it appears that the correct knowledge of the ovulatory cycle increases with higher access to the media. It must be emphasised, however, that the percentage who correctly quoted the right period of occurrence of ovulation (i.e., within the middle of the cycle) for those with regular exposure to the media (i.e., almost everyday) is highest for the newspapers $(43 \%)$ compared with radio $(31 \%)$ and television $(30 \%)$. 
Table 3: Percent distribution of sexually active young females by knowledge of the ovulatory cycle by media exposure

\begin{tabular}{|c|c|c|c|c|c|c|c|}
\hline \multirow[b]{2}{*}{ Media exposure } & \multicolumn{6}{|c|}{ Timing of ovulation in menstrual cycle } & \multirow[b]{2}{*}{$\begin{array}{l}\text { Don't } \\
\text { know }\end{array}$} \\
\hline & $\begin{array}{l}\text { During } \\
\text { her } \\
\text { period }\end{array}$ & $\begin{array}{l}\text { After } \\
\text { period } \\
\text { ends }\end{array}$ & $\begin{array}{l}\text { Middle } \\
\text { of the } \\
\text { cycle }\end{array}$ & $\begin{array}{l}\text { Before } \\
\text { period } \\
\text { begins }\end{array}$ & $\begin{array}{l}\text { At any } \\
\text { time }\end{array}$ & Other & \\
\hline \multicolumn{8}{|l|}{ Newspaper } \\
\hline Not at all & 2.9 & 31.4 & 19.3 & 4.8 & 13.2 & 0.1 & 28.3 \\
\hline Less than once a week & 1.3 & 33.6 & 32.4 & 7.1 & 4.6 & 0.0 & 21.0 \\
\hline At least once a week & 3.7 & 27.5 & 32.1 & 7.3 & 7.6 & 0.3 & 21.5 \\
\hline Almost everyday & 2.9 & 26.5 & 42.7 & 2.9 & 4.4 & 0.0 & 20.6 \\
\hline \multicolumn{8}{|l|}{ Radio } \\
\hline Not at all & 2.2 & 26.0 & 13.8 & 3.3 & 14.9 & 0.0 & 39.8 \\
\hline Less than once a week & 3.5 & 36.4 & 15.0 & 6.1 & 8.0 & 0.0 & 31.0 \\
\hline At least once a week & 2.8 & 36.8 & 18.9 & 6.4 & 11.3 & 0.1 & 23.7 \\
\hline Almost everyday & 2.8 & 26.8 & 31.2 & 4.9 & 11.1 & 0.1 & 23.1 \\
\hline \multicolumn{8}{|l|}{ Television } \\
\hline Not at all & 2.9 & 34.5 & 14.5 & 4.6 & 11.7 & 0.0 & 31.8 \\
\hline Less than once a week & 2.5 & 33.1 & 23.9 & 5.0 & 9.4 & 0.0 & 26.1 \\
\hline At least once a week & 3.8 & 30.7 & 26.0 & 6.1 & 12.2 & 0.2 & 21.0 \\
\hline Almost everyday & 2.2 & 26.1 & 29.9 & 5.4 & 10.9 & 0.2 & 25.3 \\
\hline \multirow{2}{*}{$\begin{array}{ll}\text { Total } \% & \\
& \text { Number }\end{array}$} & 2.8 & 31.0 & 23.3 & 5.3 & 11.2 & 0.1 & 26.3 \\
\hline & 60 & 667 & 502 & 113 & 242 & 2 & 567 \\
\hline
\end{tabular}

Source: Computed from 2003 GDHS data. 
Stephen O. Kwankye and Eric Augustt: Media Exposure and Reproductive Health Behaviour Among Young Females in Ghana

\section{Children Ever Born}

Analysis of the young females by the number of children ever born (CEB) lends some support to what the likely impact of a person's access to media information could be. The results show that the closeness of a young woman to the media is more likely to result in her giving birth to a smaller number of children by the end of her reproductive period. This suggests a decreasing number of CEB with higher frequency of exposure to newspapers, radio or television. At the same time, the percentage of young females who have ever had three or more children tends to be lowest among the young women who reported having access to information from the newspapers, radio or television either at least once a week or almost everyday. Overall, however, a third of the young women had had only one child at the time of the survey, $15 \%$ had had two children and just three percent had had three children or more.

\section{Pregnancy Termination}

The results from the analysis of the possible impact of a woman's access to the media on pregnancy termination among the young females do not show much consistency. As is seen in Table 4, $13 \%$ of young females who do not read newspapers at all reported to have ever terminated a pregnancy. This compares with five percent among their counterparts who read newspapers almost everyday. While $11.5 \%$ of those who read newspapers at least once a week have ever terminated a pregnancy, just about seven percent of those who read it less than once a week reported to have ever terminated a pregnancy. In terms of radio and television, the results do not show any substantial variation among the different levels of exposure to the two media types. The results suggest that one's decision to terminate a pregnancy does not appear to be dependent on the person's access to newspapers, radios or television transmissions. 
Table 4: Percent distribution of young females by whether or not they have terminated pregnancy by media exposure

\begin{tabular}{lrr}
\hline & Ever terminated a pregnancy \\
\hline Media exposure & Yes & No \\
Newspaper & 13.1 & 86.9 \\
Not at all & 6.1 & 93.4 \\
Less than once a week & 11.5 & 88.5 \\
At least once a week & 5.0 & 95.0 \\
Almost everyday & & \\
Radio & 12.8 & 87.2 \\
Not at all & 10.7 & 89.3 \\
Less than once a week & 13.0 & 87.0 \\
At least once a week & 12.1 & 87.9 \\
Almost everyday & & \\
Television & 10.5 & 89.5 \\
Not at all & 13.6 & 86.4 \\
Less than once a week & 13.5 & 86.5 \\
At least once a week & 14.1 & 85.9 \\
Almost everyday & 12.3 & 87.7 \\
Total \% & 1,141 & 159 \\
Number &
\end{tabular}

Source: Computed from 2003 GDHS data.

\section{Multivariate Analysis}

Two sets of analysis were carried out, one using multiple regression and the other employing logistic regression techniques. For the multiple regression analysis, the dependent variables were age at first sex and number of children ever born at the time of the survey. The independent variables are current age, level of education, place of residence and exposure to newspapers, radio and television. The results of the analysis are presented in Tables 5 and 6 .

From Table 5, it is observed that overall, the variables included in the model explained $23 \%$ of the variation in age at first sex among the young women age 15-24 years. It is also noted that although the relationship suggests some increasing age at first sex as frequency of exposure to the three media types increases, the results do not show any statistical significance particularly for radio and television. In the case of newspapers, the results are statistically significant with regard 
Stephen O. Kwankye and Eric Augustt: Media Exposure and Reproductive Health Behaviour Among Young Females in Ghana

to persons who read newspapers at least once a week or almost everyday i.e., at slightly higher than $90 \%$ level of confidence. The analysis of the radio is also statistically significant with regard to only persons who listen to it almost everyday $(\mathrm{p}<0.05)$.

Furthermore, the results lend support to a higher age at first sex among young females in urban areas compared with others resident in rural communities. Similarly, there is some direct relationship between education and age at first sex especially at postprimary school levels ( $p<0.05)$. It is also important to note that current age relates directly with age at first sex, suggesting that age at first sex has declined between the two age cohorts (15-19 and 20-24 years) in Ghana.

Table 5: Results of multiple regression analysis on age at first sex among females age 15-24 years in Ghana

\begin{tabular}{llll}
\hline Variable & B & SE & Beta \\
\hline Current Age & $.3317^{* * *}$ & .0212 & .3886 \\
Education & & & \\
No Education & $\mathrm{RC}$ & & \\
Primary & -.1231 & .1626 & -.0247 \\
Secondary & $.3216^{* *}$ & .1525 & .0760 \\
Higher & $1.8430^{* * *}$ & .4398 & .1147 \\
Place of residence & & & \\
Rural & $\mathrm{RC}$ & & \\
Urban & $.2635^{* *}$ & .1149 & .0625 \\
Exposure to Newspapers & & & \\
Not at all & $\mathrm{RC}$ & & \\
Less than once a week & .2694 & .1866 & .0374 \\
At least once a week & $.3806^{* *}$ & .2995 & .0510 \\
Almost everyday & $.8260^{* *}$ & .4352 & .0481 \\
Exposure to Radio & & & \\
Not at all & $\mathrm{RC}$ & & \\
Less than once a week & .0441 & .2098 & .0069 \\
At least once a week & .2760 & .1803 & .0602 \\
Almost everyday & $.3757^{* *}$ & .1772 & .0889 \\
Exposure to Television & & & \\
Not at all & $\mathrm{RC}$ & & \\
\hline
\end{tabular}


African Population Studies Vol. $22 n^{\circ} 2$ /Etude de la Population Africaine Vol. $22 N^{\circ} 2$

\begin{tabular}{llll}
\hline Less than once a week & .0676 & .1567 & .0124 \\
At least once a week & .0968 & .1509 & .0198 \\
Almost everyday & $.1886^{* * *}$ & .1629 & .0381 \\
Constant & & \\
\hline Multiple $\mathrm{R}=.48007$ & $\mathrm{RC}=$ Reference category \\
$\mathrm{R}^{2}=.23047$ & ${ }^{* * *} \mathrm{p}<.001{ }^{* *} \mathrm{p}<.05 ;{ }^{*} \mathrm{p}<.10$ \\
Adjusted $\mathrm{R}^{2}=.22208$ & & \\
Source: Computed from 2003 GDHS data.
\end{tabular}

The results of the multiple regression analysis on children ever born in Table 6 indicate that regular exposure to the television and newspapers is statistically significant in explaining the variation in children ever born among the young females. Thus, exposure to the television or newspapers relates inversely with number of children ever born. The relationship between the radio and the number of children ever born is on the other hand, statistically not significant. At the same time, urban dwellers have a smaller number of children ever born compared with their rural counterparts while education exhibits indirect relationship with children ever born. In terms of age, the results show a direct relationship with children ever born where the older females tend to have relatively higher number of children ever born compared with the younger ones (Table 6). This is, however, very much to be expected.

Table 6: Results of multiple regression analysis on the number of children ever born among females age 15-24 years in Ghana

\begin{tabular}{llll}
\hline Variable & B & SE & Beta \\
\hline Current Age & $.1349^{* * *}$ & .0046 & .5143 \\
Education & & & \\
No Education & RC & & \\
Primary & $-.0825^{*}$ & .0431 & -.0459 \\
Secondary & $-.2560^{* * *}$ & .0405 & -.1688 \\
Higher & $-.7254^{* * *}$ & .0954 & -.1513 \\
Place of residence & & & \\
Rural & $\mathrm{RC}$ & & \\
Urban & $-.1879^{* * *}$ & .0289 & -.1261 \\
Exposure to Newspapers & & & \\
Not at all & $\mathrm{RC}$ & & \\
Less than once a week & $-.1370^{* * *}$ & .0434 & -.0579 \\
At least once a week & $-.1438^{* * *}$ & .0419 & -.0671 \\
\hline
\end{tabular}


Stephen O. Kwankye and Eric Augustt: Media Exposure and Reproductive Health Behaviour Among Young Females in Ghana

\begin{tabular}{|c|c|c|c|}
\hline Almost everyday & $-.2416^{* * *}$ & .0773 & -.0571 \\
\hline \multicolumn{4}{|l|}{ Exposure to Radio } \\
\hline Not at all & $\mathrm{RC}$ & & \\
\hline Less than once a week & .0335 & .0519 & .0148 \\
\hline At least once a week & .0240 & .0445 & .0148 \\
\hline Almost everyday & -.0067 & .0437 & -.0045 \\
\hline \multicolumn{4}{|l|}{ Exposure to Television } \\
\hline Not at all & $\mathrm{RC}$ & & \\
\hline Less than once a week & -.0214 & .0405 & -.0107 \\
\hline At least once a week & $-.1192^{* * *}$ & .0379 & -.0688 \\
\hline Almost everyday & $-.1090 * * *$ & .0398 & -.0666 \\
\hline Constant & $-1.7741^{* * *}$ & .1000 & - \\
\hline Multiple $\mathrm{R}=.61344$ & \multicolumn{3}{|c|}{$\mathrm{RC}=$ Reference category } \\
\hline $\mathrm{R}^{2}=.37630$ & \multirow{2}{*}{\multicolumn{3}{|c|}{${ }^{* *} p<.001 ;{ }^{* *} p<.05 ; * p<.10$}} \\
\hline Adjusted $R^{2}=.37223$ & & & \\
\hline
\end{tabular}

Table 7 presents the results of logistic analysis on knowledge of ovulatory cycle among the young females in Ghana. From the results, females of age 20-24 years are almost two times as likely to know the correct timing of ovulation compared with their younger colleagues of 15-19 years. In terms of education, there is apparently no significant difference between females of primary vis-à-vis those with no education. However, females with secondary or higher level of education are two times more likely to have knowledge of the ovulatory cycle relative to uneducated females. Compared with rural residents, urban females are almost one and a half times more likely to have knowledge of the correct timing of ovulation in a woman's menstrual cycle.

The analysis further shows that a female's exposure to newspapers in particular directly relates to her knowledge of the ovulatory cycle. For example, females who read newspapers almost everyday are two times more likely to know the accurate occurrence of ovulation relative to their counterparts who do not read at all. On the other hand, exposure to radio produces quite a statistically significant result only among females who listen to radio almost everyday i.e., such persons have slightly higher than one and a half chances of accurately reporting the timing of ovulation in the woman's menstrual cycle. Similarly, the effects of one's exposure to 
television suggest that those who watch television at least once a week or almost everyday are also one and a half times more likely to report accurately the timing of ovulation than those who never watch it.

Table 7: Results of logistic regression analysis on knowledge of ovulatory cycle among females age 15-24 years in Ghana

\begin{tabular}{|c|c|c|c|}
\hline Variable & $\begin{array}{l}\text { Logistic co- } \\
\text { efficient }\end{array}$ & $\begin{array}{l}\text { Standard } \\
\text { error }\end{array}$ & Odds ratio \\
\hline \multicolumn{4}{|l|}{ Current Age } \\
\hline $15-19(\mathrm{RC})$ & & & 1.000 \\
\hline $20-24$ & 0.691 & 0.111 & $1.996^{* * *}$ \\
\hline \multicolumn{4}{|l|}{ Education } \\
\hline No Education (RC) & & & 1.000 \\
\hline Primary & 0.135 & 0.219 & 1.145 \\
\hline Secondary & 0.769 & 0.197 & $2.158^{* * *}$ \\
\hline Higher & 0.661 & 0.361 & $1.937^{*}$ \\
\hline \multicolumn{4}{|l|}{ Place of residence } \\
\hline Rural (RC) & & & 1.000 \\
\hline Urban & 0.336 & 0.122 & $1.399 * * *$ \\
\hline \multicolumn{4}{|l|}{ Exposure to Newspapers } \\
\hline Not at all (RC) & & & 1.000 \\
\hline Less than once a week & 0.323 & 0.166 & $1.381^{* *}$ \\
\hline At least once a week & 0.412 & 0.162 & $1.510^{* *}$ \\
\hline Almost everyday & 0.614 & 0.276 & $1.847^{* *}$ \\
\hline \multicolumn{4}{|l|}{ Exposure to Radio } \\
\hline Not at all (RC) & & & 1.000 \\
\hline Less than once a week & -0.078 & 0.258 & 0.925 \\
\hline At least once a week & -0.042 & 0.216 & 0.959 \\
\hline Almost everyday & 0.512 & 0.206 & $1.668^{* *}$ \\
\hline \multicolumn{4}{|l|}{ Exposure to Television } \\
\hline Not at all (RC) & & & 1.000 \\
\hline Less than once a week & 0.399 & 0.178 & $1.491^{* *}$ \\
\hline At least once a week & 0.520 & 0.166 & $1.682^{* * *}$ \\
\hline Almost everyday & 0.496 & 0.171 & $1.641^{* * *}$ \\
\hline Constant & -2.975 & 0.261 & $0.051^{* * *}$ \\
\hline
\end{tabular}

With regard to ever use of any family planning method, Table 8 shows that young females of 20-24 years are five times more likely 100 
Stephen O. Kwankye and Eric Augustt: Media Exposure and Reproductive Health Behaviour Among Young Females in Ghana

to have ever used a family planning method compared with females of 15-19 years. Yet, in terms of current use of any family planning method, females aged 20-24 years are three times more likely to use any family planning method relative to their counterparts of 15-19 years (see Table 9). It is also noted that education relates directly with ever and current use of any family planning method among young females in Ghana. For example, with regard to either ever use or current use of any family planning method females with higher level of education are a little more than twice likely to ever use or currently use any method of contraception compared with their counterparts with no education $(\mathrm{p}<0.001)$.

Table 8: Results of logistic regression analysis on ever use of any family planning method among females age 15-24 years in Ghana

\begin{tabular}{|c|c|c|c|}
\hline Variable & $\begin{array}{l}\text { Logistic co- } \\
\text { efficient }\end{array}$ & $\begin{array}{l}\text { Standard } \\
\text { error }\end{array}$ & Odds ratio \\
\hline \multicolumn{4}{|l|}{ Current Age } \\
\hline 15-19 (RC) & & & 1.000 \\
\hline $20-24$ & 1.609 & 0.105 & $5.000 * * *$ \\
\hline \multicolumn{4}{|l|}{ Education } \\
\hline No Education (RC) & & & 1.000 \\
\hline Primary & 1.088 & 0.185 & $2.967 * * *$ \\
\hline Secondary & 1.281 & 0.175 & $3.600 * * *$ \\
\hline Higher & 0.890 & 0.353 & $2.436^{* *}$ \\
\hline \multicolumn{4}{|l|}{ Place of residence } \\
\hline Rural (RC) & & & 1.000 \\
\hline Urban & 0.174 & 0.113 & 1.190 \\
\hline \multicolumn{4}{|l|}{ Exposure to Newspapers } \\
\hline Not at all (RC) & & & 1.000 \\
\hline Less than once a week & -0.189 & 0.164 & 0.828 \\
\hline At least once a week & -0.428 & 0.165 & $0.652^{* * *}$ \\
\hline Almost everyday & -1.036 & 0.327 & $0.355^{* * *}$ \\
\hline \multicolumn{4}{|l|}{ Exposure to Radio } \\
\hline Not at all (RC) & & & 1.000 \\
\hline Less than once a week & 0.338 & 0.222 & 1.402 \\
\hline At least once a week & 0.469 & 0.190 & $1.598^{* *}$ \\
\hline Almost everyday & 0.557 & 0.186 & $1.745^{* * *}$ \\
\hline \multicolumn{4}{|l|}{ Exposure to Television } \\
\hline Not at all (RC) & & & 1.000 \\
\hline
\end{tabular}


African Population Studies Vol. $22 n^{\circ} 2$ /Etude de la Population Africaine Vol. $22 N^{\circ} 2$

\begin{tabular}{lrcl}
\hline Less than once a week & 0.438 & 0.158 & $1.550^{* * *}$ \\
At least once a week & 0.618 & 0.149 & $1.854^{* * *}$ \\
Almost everyday & 0.292 & 0.158 & $1.339^{*}$ \\
Constant & -3.286 & 0.240 & $0.037^{* * *}$ \\
\hline RC = Reference category & $* * *$ & $p<.001 ;{ }^{* *} \mathrm{p}<.05 ;{ }^{*} \mathrm{p}<.10$ \\
\multicolumn{4}{c}{ Source: Computed from 2003 GDHS data. }
\end{tabular}

The results further show that the importance of exposure to the media is relatively more visible with reference to ever use of any family planning method by young women than current contraceptive use. For example, with regard to current contraceptive use, the results are only statistically significant in terms of a female's exposure to the radio especially where exposure is almost everyday i.e., such persons are more than twice likely to currently use any family planning method relative to their counterparts who never listen to the radio (Table 9). On the other hand, the results regarding the relationship between media exposure and ever use of family planning though statistically significant in several respects are not consistent. For example, quite unexpectedly, it appears that the more a female is exposed to newspapers, the less likely she would ever use any contraceptive method (Table 8). However, for radio and television, the reverse is the case where for example, females who listen to the radio almost everyday are close to two times more likely to ever use any family planning method relative to their counterparts who never listen to it.

Table 9: Results of logistic regression analysis on current use any family planning method among females age 15-24 years in Ghana

\begin{tabular}{llll}
\hline Variable & $\begin{array}{l}\text { Logistic } \\
\text { efficient }\end{array}$ & $\begin{array}{l}\text { Standard } \\
\text { error }\end{array}$ & Odds ratio \\
\hline $\begin{array}{l}\text { Current Age } \\
\text { 15-19 (RC) }\end{array}$ & & & \\
20-24 & 1.106 & 0.136 & 3.000 \\
Education & & & \\
No Education (RC) & & & 1.000 \\
Primary & 0.654 & 0.264 & $1.923^{* * *}$ \\
Secondary & 0.859 & 0.247 & $2.360^{* * *}$ \\
Higher & 0.846 & 0.426 & $2.330^{* *}$ \\
Place of residence & & & \\
\hline
\end{tabular}


Stephen O. Kwankye and Eric Augustt: Media Exposure and Reproductive Health Behaviour Among Young Females in Ghana

\begin{tabular}{lccc}
\hline Rural (RC) & & & 1.000 \\
Urban & -0.026 & 0.143 & 0.856 \\
Exposure to Newspapers & & & \\
Not at all (RC) & & 0.199 & 1.000 \\
Less than once a week & 0.108 & 1.114 \\
At least once a week & 0.184 & 0.196 & 1.202 \\
Almost everyday & -0.246 & 0.382 & 0.782 \\
Exposure to Radio & & & \\
Not at all (RC) & & & 1.000 \\
Less than once a week & 0.298 & 0.340 & 1.347 \\
At least once a week & 0.632 & 0.287 & $1.881^{* *}$ \\
Almost everyday & 0.880 & 0.280 & $2.412^{* * *}$ \\
Exposure to Television & & & \\
Not at all (RC) & & & 1.000 \\
Less than once a week & 0.362 & 0.203 & $1.436^{*}$ \\
At least once a week & 0.388 & 0.192 & $1.473^{* *}$ \\
Almost everyday & -0.035 & 0.206 & 0.966 \\
Constant & -3.956 & 0.350 & $0.000^{* *}$ \\
\hline RC = Reference category & $* * *$ & $\mathrm{p}<.001 ;{ }^{* *} \mathrm{p}<.05 ;{ }^{*} \mathrm{p}<.10$ \\
Source: Computed from $2003 \mathrm{GDHS}$ data. &
\end{tabular}

\section{Discussion}

The results of the analysis point to some positive impacts exposure to the media could make on attitudes and behaviours of young females regarding sexuality and reproductive health. First, from the bivariate analysis, it has been established in this paper that females who are regularly exposed to the three media sources exhibit the highest age at first sex and marriage. Again, knowledge and use of contraception are both highest among females who are exposed to newspapers, the radio and television almost everyday. Similar results were found in respect of the analysis of knowledge of the ovulatory cycle. Quite consistently also, females who are regularly exposed to the media have relatively lower number of children ever born. In contrast, analysis of the effect of the media on pregnancy termination does not produce any consistent results. It is thus, not clear as to what extent exposure to the media encourages or discourages pregnancy termination among the young females. 
From the multivariate analysis, however, the results are not clear-cut in several respects. For example, while the radio and television do not show statistically significant influence on age at first sex, in contrast, exposure to newspapers exhibits high level of significance. This could plausibly be linked to education where a female's exposure to newspapers would depend largely on her education i.e., her ability to read and/or write compared to the radio or television, which are audio-visual. It could also be that newspapers provide more educative information about dangers of early sex relative to the radio or television.

With respect to number of children ever born, the highest level of statistical significance is attained by exposure to newspapers, followed by television with radio showing no statistical significance. Again, in terms of knowledge of the ovulatory cycle, the radio once again does not appear to be an important influencing source of information relative to newspapers and television. It is, however, interesting to note that exposure to the radio appears to show more consistently significant impact on ever and current use of any family planning method compared with either the newspaper or the television. Perhaps, this has arisen due to the regular radio advertisements on family planning and birth control in Ghana. In fact, for either ever use or current use of any family planning method, exposure to newspapers does not show any meaningful impact. This is because newspapers carry few or none contraceptive advertisements and hence regularly reading newspapers may have little or no impact on a female's use or non-use of any family planning method. Perhaps what is important is not just one's mere exposure to the media but the contents of the media that one is exposed to. This is because, if a particular media source one is exposed to does not carry educative information on sexuality and reproductive health issues, one's behaviour would not have any impact irrespective of his/her exposure to it everyday.

With regard to the other background variables, namely current age, education and place of residence, the results pertaining to the dependent variables are to be expected. For example, urban residents have higher age at first sex, lower number of children ever born and higher knowledge of the ovulatory cycle and are more likely to ever use any method of family planning relative to their counterparts from rural areas. This is may be due in part to the fact that information on 
Stephen O. Kwankye and Eric Augustt: Media Exposure and Reproductive Health Behaviour Among Young Females in Ghana

fertility, birth control and reproductive health related issues are more available or disseminated within the urban environment compared with the rural areas. In addition, it also has to do with the role of education, which in Ghana is higher in the urban vis-à-vis the rural areas (Ghana Statistical Service, 2002). It is, however, important to note that the analysis depicts a lower age at first sex among females of 15-19 years compared with those of 20-24 years. This shows that although the population have had sex within ages 15-19 years has declined in recent years (Kwankye, 2005), the timing of first sex among the few that ever had sex is declining and should be addressed.

\section{Conclusions and Recommendations}

The role of the media role in all facets of life is well acknowledged especially in the current situation of information, communication and technology. As Okonofua (1997) acknowledges, targeting the press could assist in reshaping community attitudes for example towards induced abortion. Among young women, however, this paper has demonstrated that newspapers are better placed to positively influence attitudes towards sex, fertility, contraceptive use and reproductive health in general compared with the radio or television. This is perhaps the case because the radio and television have not placed emphasis on programmes on reproductive health that target the youth. This calls for some re-orientation of some of the programmes that are broadcast on the numerous radio stations and the few television studios in the country in order to make more positive impacts on the attitudes of the youth who are considered the future leaders of the nation. For example, as Tawiah (2002) posits, "it is quite obvious that neglecting the reproductive health needs of adolescents and the youth who form a significant proportion of the population of sub-Saharan Africa will have long-term adverse effects on the capabilities of our next generation, in particular women".

The Ministry of Education and Sports together with the Ghana Education Service should have programmes that encourage reading of newspapers in schools and colleges in Ghana. School heads should do some content analysis of the newspapers and make a sustained subscription to those that devote more attention to development and reproductive health issues for their school libraries. When editors and 
publishers of newspapers realise that the more they focus on development and reproductive health issues, their tabloids would attract sustained subscription by schools and colleges, more and more of them would join in the crusade on reproductive health attitudinal change in the country.

Furthermore, based on the finding of the importance of newspapers in impacting on the attitudes and behaviour of young females on sexual and reproductive health, the Ministry of Information and National Orientation, Ghana AIDS Commission and reproductive health advocates in Ghana should target newspaper editors and publishers for advocacy for them to devote more prominent spaces of their tabloids for sexual and reproductive health issues on young persons in Ghana. Similarly, these Ministries, Departments and Agencies should target radio and television stations for advocacy to do more reproductive health programmes with special emphasis on the rural areas considering that rural areas in Ghana have little or no access to newspapers. This should be rigorously pursued considering that most of the radio stations and newspapers have private ownership whose main objective is profit making.

Finally, there is the need for a special study on the impact of the mass media on sexual and reproductive health of young persons. Such a study would provide an opportunity to consider more variables in the analysis since using data from the national demographic and health survey tends to place a limitation on the variables one could use in analysing the relationship between media exposure and sexual/reproductive health attitudinal change. This study should not focus on mere exposure of the individual to the media, but most importantly should find out about the contents of the media coverage of sexuality and reproductive health issues in order to draw conclusions as to the role of the media in changing the attitudes of young people about sexual and reproductive health issues in Ghana. 
Stephen O. Kwankye and Eric Augustt: Media Exposure and Reproductive Health Behaviour Among Young Females in Ghana

\section{REFERENCES}

Centre on Population Options, 1992. Adolescents and unsafe abortion in developing countries: a preventable tragedy. Based on the proceedings from the International Forum on Adolescent Fertility. Washington D.C. International Center for Population Options.

Central Statistical Office (Zambia) and Ministry of Health and Macro InternationalInc. 1997. Zambia Demographic and Health Survey, 1996. Calverton, Maryland: Central Statistical Office and Macro International Inc.

Essah, E. 2006. School Children Learning about Sex and Love. Oppong Christine, Oppong M. Yaa P.A, Odotei Irene K. Sex and Gender in an Era of AIDS, Ghana at the Turn of the Millennium. Sub-Saharan Publishers, Legon, Accra.

Ghana Statistical Service, Noguchi Memorial Institute for Medical Research (NMIMR), and ORC Macro. 2004. Ghana Demographic and Health Survey 2003. Calverton, Maryland: Ghana Statistical Service, NMIMR, and Macro International Inc.

Ghana Statistical Service, 2002. Ghana Population and Housing Census. Ghana Statistical Service. Accra.

Ghana Statistical Service, Noguchi Memorial Institute for Medical Research (NMIMR), and ORC Macro. 2004. Ghana Demographic and Health Survey 2003. Calverton, Maryland: Ghana Statistical Service, and Macro International Inc.

1994. Ghana Demographic and Health Survey 1993.

Calverton, Maryland: Ghana Statistical Service, and Macro International Inc.

1989. Ghana Demographic and Health Survey 1988.

Calverton, Maryland: Ghana Statistical Service, and Macro International Inc.

Kwankye, S.O. 2005. "Female Adolescent and Reproductive Change in Ghana: Evidence from Cape Coast and Mankrong". Reproductive Change in 
Ghana: Recent Patterns and Future Prospects. Edited by Agyei-Mensah, S.,Casterline, J.B. and Agyeman, D.K. Department of Geography and Resource Development, University of Ghana, Legon, April 2005, pp. 53-100.

Ling, J. 1990. “Communicating Disease through Words and Images”. Development Communication Report. Clearinghouse on Development Communication, vol. 4, no. 71, pp.1-2.

McCurie, W.I. 1981. "Theoretical foundations of Campaigns". In Rice, R.E. and Paisley, W.I., eds. Public Communication Campaigns. Beverly Hills, California, Sage Publications, pp. 41-70.

McCurie, W.I. 1986. “The Myth of Massive Media Impacts: Savagings and salvagings". Public Communication and Behaviour, vol. 1, pp.173257.

Nabila, J.S., Fayorsey, C. and Pappoe, M. 1996. Youth Reproductive Health in Africa: Assessment of Adolescent Reproductive Health Needs in Ghana. UNFPA, USAID, CEDPA and JHU/PCS, Accra.

Nyarko, P.E. 2005. Fertility Levels, Patterns and Trends. Ghana Population Analysis Report. Volume 1. Socio-Economic and Demographic Trends. Ghana Statistical Service, Accra. pp. 139-177.

Okonofua, F. 1997. "Preventing Unsafe Abortion in Nigeria". African Journal of Reproductive Health, vol. 1, no. 1. F.E. Okonofua and R.C. Snow (eds.), pp. 25-36.

Population Reference Bureau. 2005. 2005 World Population Data Sheet. Population Reference Bureau, New York.

Tawiah, E.O. 2002. "Adolescent Fertility and Reproductive Health in Four sub-Saharan African Countries". African Population Studies, vol. 17, no. 2, pp. 81-98. 